\title{
Degradation of Mechanical Properties of Casing Pipe in the Acidic Environment
}

\author{
Zhi Liu \\ Xi'an Research Institute,CCTEG,Xi'an710077,China \\ email:liuzhi030191@sina.com
}

Keywords: Casing pipe; Corrosion; Mechanical; Properties

\begin{abstract}
In the present work ,according to the present situation that casing pipe are frequently applied in the high temperature environment containing hydrogen sulfide and carbon dioxide, degradation of mechanical properties of casing pipe in the environment with hydrogen sulfide and carbon dioxide is also investigated in the paper. The results show that degradation of mechanical properties of casing pipe is serious, the biggest decreased degree of P110S and P110 are 13.71\% and $13.02 \%$ respectively. It is considered through analysis that the main reason of degradation of casing pipe in the Carbon dioxide environment is related to the localized corrosion on the steel surface. The degradation of mechanical properties of carbon steel is analysed with the relations between elastic modulus and hydrogen effects on atomic binding force in this paper.
\end{abstract}

\section{Introduction}

The casing pipe is widely used in coal mine machinery, which are composed of carbon steel has become the most important engineering metal material, with its superior mechanical properties, good thermal conductivity and electrical conductivity and some special properties[1-2]. Using the casing pipe gradually produce damage or deterioration, or corrosion, because metal materials are inevitably influenced by the surrounding environment. Damage of the carbon steel is caused by acidic environmental and material interaction. Corrosion often can cause degradation of mechanical properties of casing pipe and bring huge economic losses[3].

\section{Testing methods}

\section{Experimental material}

Carbon steels are frequently used in the field of coal mine machinery, casing pipe P110 and P110S as the representative of material in the experiment.

\section{Analysis methods}

According to the GB/T 229-1994[4], the tensile and impact specimens are machined by the different proportion.

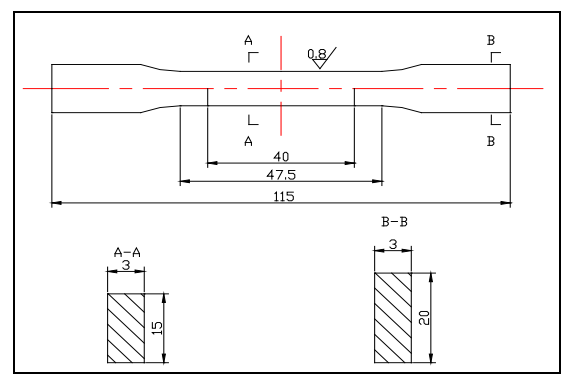

Fig. 1:Schematics of the tensile and impact specimens at the high temperature and pressure condition containing $\mathrm{H} 2 \mathrm{~S} / \mathrm{CO} 2$

\section{Testing equipments}

Testing equipments includes the high temperature and pressure reactor, constant temperature water bath, FC impact testing machine, MTS universal testing machine, scanning electron microscope (SEM) and so on. In the high temperature and pressure condition containing H2S/CO2 
testing.

\section{Testing condition}

The experiment was making in the high temperature and pressure reactor, experimental solution includes: Cl- was $50000 \mathrm{mg} / \mathrm{L}$, Ca2+ was $15000 \mathrm{mg} / \mathrm{L}, \mathrm{Mg} 2+$ was $6000 \mathrm{mg} / \mathrm{L}$, $\mathrm{Na}+$ was $1500 \mathrm{mg} / \mathrm{L}, \mathrm{K}+$ was $1000 \mathrm{mg} / \mathrm{L}, \mathrm{pH}=4.5$, the whole pressure was $20 \mathrm{MPa}$, corrosion time was 168 hours.

\section{Experiment results and discussions}

The influence of high temperature and pressure $\mathrm{H}_{2} \mathrm{~S} / \mathrm{CO}_{2}$ for the tensile properties

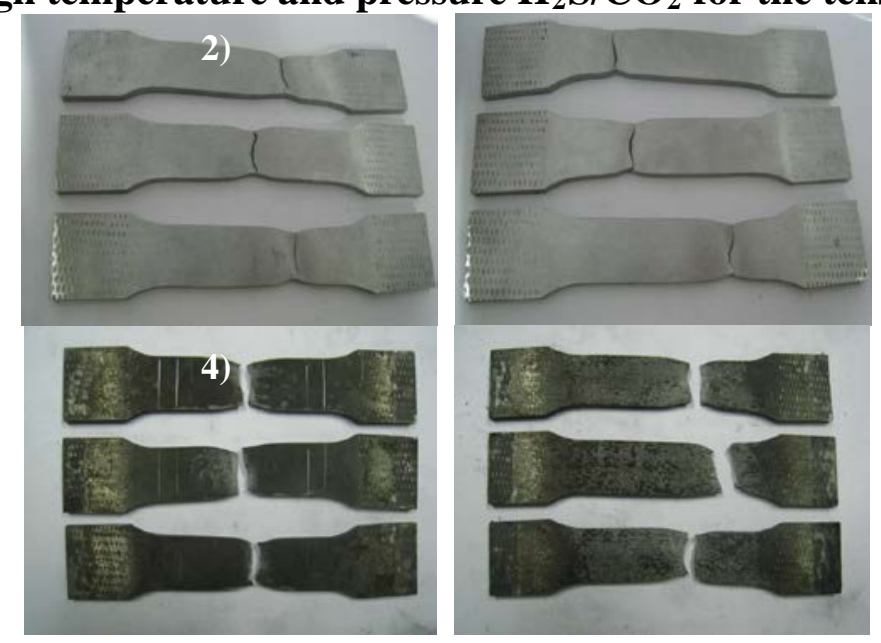

1):No corrosion(P110); 2):No corrosion(P110S);

3):After corrosion(P110); 4):After corrosion(P110S)

Fig. 2: Macrophotographs of tubing and casing after tensile test

Fig.2 is macrophotographs of tubing and casing after tensile test. It can show the difference of plasticity after tensile test. No corrosion, P110 and P110S exist plastic deformation at the fracture, necking deformation is obvious; After corrosion, there is little necking deformation, show that plasticity of material had decreased after high temperature and pressure H2S/CO2 corrosion.

The influence of partial pressure of $\mathrm{H}_{2} \mathrm{~S}$ for the tensile properties

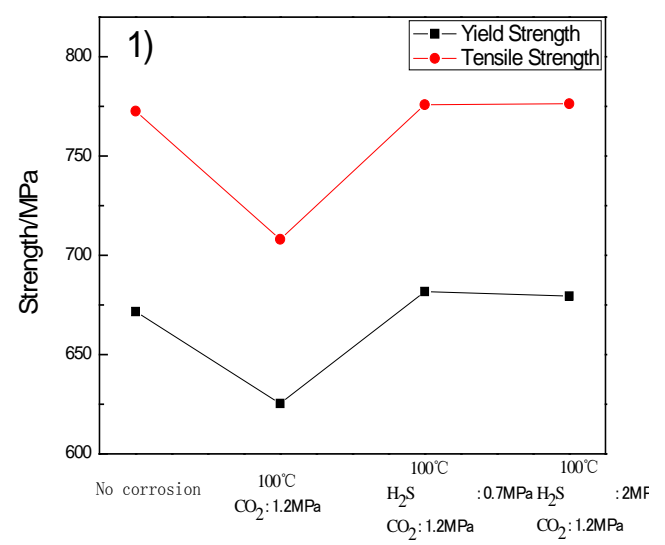




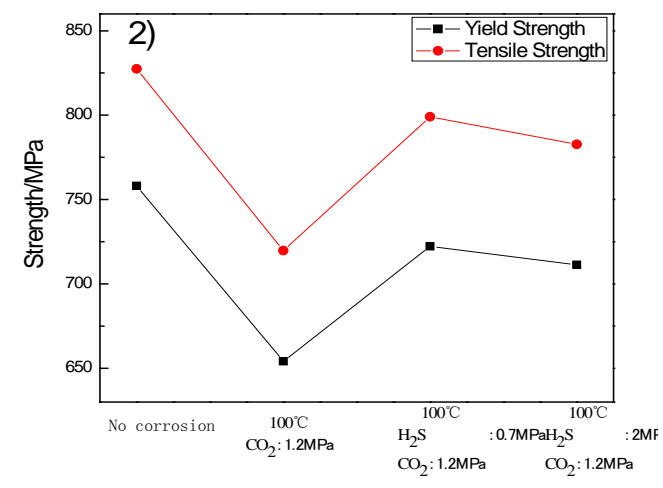

1):P110; 2):P110S

Fig. 3:Schematic diagrams of tensile strength of tubing and casing

Fig. 3 shows that the tensile of P110 and P110S obviously decreased at the pure CO2 condition, the biggest decreased degree of $\mathrm{P} 110 \mathrm{~S}$ and $\mathrm{P} 110$ are $13.71 \%$ and $13.02 \%$ respectively. The mechanism of CO2 corrosion is: CO2 corrosion is different between the cathode and the anode, the ferric of the anode continuously saluting lead to the localized corrosion on the steel surface; In the cathode, $\mathrm{CO} 2$ saluted water form carbonic acid, releasing out $\mathrm{H}+$ as depolarizer easily seize electrons , then promoting to the anode solute result in corrosion.

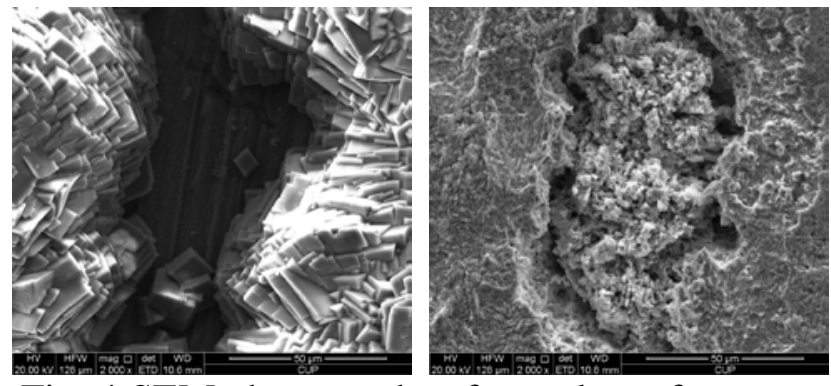

Fig. 4:SEM photographs of sample surface

Fig. 4 show that tubing and casing occur localized corrosion after pure $\mathrm{CO} 2$ corrosion, according to the same sample under the same condition. It is considered through analysis that the main reason of degradation of casing pipe in the $\mathrm{CO} 2$ environment is related to the localized corrosion on the steel surface.

The paper discusses the influence degree of Hydrogen atom by material elastic modulus after corrosion. Because elastic modulus is related to the force of atom $\sigma \mathrm{m}[5]$.

$$
\sigma_{m}=\left(\left|\frac{E \Gamma}{b}\right|\right)^{1 / 2}
$$

The $\Gamma$ represents surface energy, the b represents interatomic distance. If Hydrogen energy can decrease elastic modulus, it means Hydrogen energy can decrease the atomic bonding force. The elastic modulus of P110 and P110S have little variation after high temperature and pressure $\mathrm{H} 2 \mathrm{~S} / \mathrm{CO} 2$, the influence of Hydrogen atom is small, infiltrating Hydrogen atom can not influence material mechanical properties.

It is considered through analysis that corrosion product film of XRD, corrosion product is FeS after adding H2S, as the Fig. $5 \mathrm{H} 2 \mathrm{~S}$ corrosion play a dominant role in high temperature and pressure $\mathrm{H} 2 \mathrm{~S} / \mathrm{CO} 2$ condition, most of corrosion product is sulfide. Because $\mathrm{S}$ atom has stronger providing electron ability, easily formed coordinate bond with ferric atom, adhesive force of the steel surface with corrosion product film was strengthened, decrease the degree of corrosion. 

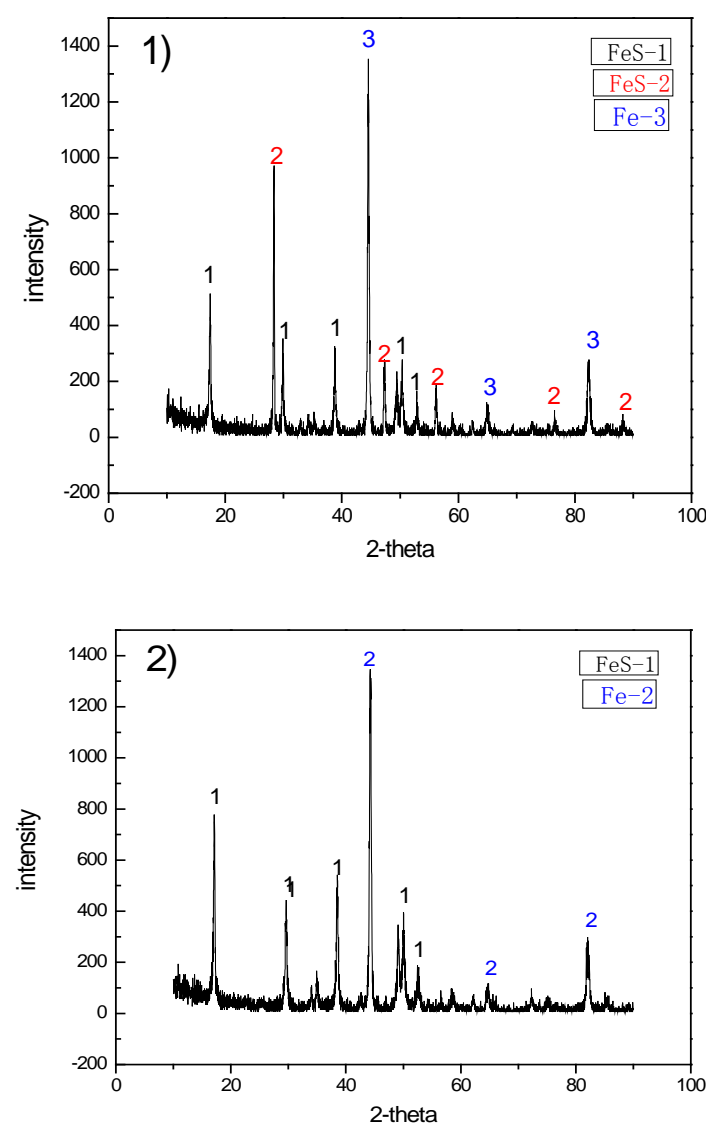

(H2S:0.7MPa,CO2:1.2MPa, $100^{\circ} \mathrm{C}$ ) 1):P110; 2):P110S

Fig. 5: XRD spectrums of corrosion product film of tubing and casing

\section{Conclusions}

All the analysis show that in comparison to pure $\mathrm{CO} 2$, the tensile strength damage was obviously decreased in the high temperature and pressure H2S/CO2 condition; when partial pressure of H2S increase from $0.7 \mathrm{MPa}$ to $2 \mathrm{MPa}$, there is little variation tensile strength between P110 and P110S maybe CO2 existence hinder the infiltration of Hydrogen atom .

\section{References}

[1] NACE RP 0472-2005, Met hods and Cont rols to Prevent In Service Environmental Cracking of Carbon Steel Weldments in Corrosive Petroleum Refining Environments [S] .

[2] Brill,T., M,J., Le CaleZ,C., Demichel,E., Nichols,F., Zapata BermudeZ. Electeomagnetic CasingInspection Tool For Corrosion Evaluation. The International Petroleum Technology Conference . 2012.

[3] Yuewen Fu, Runqiao Yu, Xuewen Peng, Shangkun Ren. Investigation of casing inspection through tubing with pulsed eddy current[J]. Nondestructive Testing and Evaluation . 2012 (4).

[4] Metal charpy notch impact test method,GB/T 229-1994.

[5] A Mechanistic Model for Carbon Dioxide Corrosion of Mild Steel in the Presence of Protective Iron Carbonate Films-Part 3. Corrosion . 2003. 